\title{
The long and winding road from silica exposure to silicosis and other health effects
}

\section{P Cocco}

\section{Silicosis is still a major threat for workers in developing countries}

$\mathrm{T}$ echnological advances over the past half century, including wet drilling and improved ventilation, have contributed to substantially reducing the occurrence of silicosis among miners and other dust exposed workers. Hundreds of cases are, however, still identified each year in Europe and the USA, ${ }^{2}$ and silicosis is a major threat for workers in developing countries. Low salaries and less restricting and/or less enforced occupational hygiene standards have attracted many environmentally and occupationally demanding productions, ${ }^{3}$ and facilitated mining initiatives in developing countries. ${ }^{4}$

On the other hand, the "reappearance" of silicosis in wealthy western countries has resulted from the extension of occupational health surveillance to previously under scrutinised small or family owned businesses, and the immigration and illegal employment of nonunionised workforce from developing countries. Furthermore, the progressive clearing of the dark and thick cloud of silicosis cases, has been accompanied by the emergence of other diseases such as lung cancer, kidney failure, and immune system disorders, ${ }^{1}$ which has rekindled the interest in silica research.

\section{"The interaction between physical and biological entities is complex"}

As in many other fields of science, it seems that the more we progress in knowledge, the more we realise the complexity of the interaction between physical and biological entities. Such a complexity is viewed differently from different perspectives, as reflected by the diverse philosophy underlying the OSHA dust permissible exposure limit, which is flexible depending on the silica content in respirable dust $\left(5 \mathrm{mg} / \mathrm{m}^{3}\right.$ in the absence of silica), in respect to the 50 $\mu \mathrm{g} / \mathrm{m}^{3}$ NIOSH silica recommended exposure limit and the silica ACGIH threshold limit value, which are independent on its dilution in respirable dust.

Studies of dose-response effects following silica exposure have traditionally sure to low levels.

relied on simple cumulative exposure estimates, in which silica concentration and duration of exposure (in years) have been given the same weight. Cumulative silica exposure was the best predictor of disease, followed by duration of exposure and average exposure among South Dakota gold miners. ${ }^{5}$ The linear doseresponse of silicosis risk by cumulative exposure has also been used as an indirect validation of exposure assessment among Chinese miners. ${ }^{6}$ Summary estimates of cumulative exposure provided comparable results to estimates weighted by the time since the exposure occurred in a study of silicosis latency. On the other hand, a fivefold range in silicosis risk by type of trade was shown among Chinese workers in association with comparable levels of cumulative exposure to silica, ${ }^{6}$ and while Hnizdo and Sluis-Cremer found that no silicosis occurred when cumulative exposure was below $0.9 \mathrm{mg} / \mathrm{m}^{3}$-years among South African gold miners, ${ }^{8}$ no cumulative exposure category was exempted from risk of silicosis in the South Dakota gold miners cohort. ${ }^{5}$ South Dakota cases with lowest cumulative exposure were exposed in the most recent years (lower levels) and had short duration of exposure, which would suggest that some men get silicosis after only brief expo-

\section{"Short term exposures to high silica concentrations might account for occurrence of silicosis at low cumulative or average exposure levels"}

However, in this issue of $O E M$, Buchanan et al show that given comparable levels of cumulative silica exposure, a silica concentration above $2 \mathrm{mg} / \mathrm{m}^{3}$, such as that which accidentally occurred in a Scottish colliery in the 1970s, is three times more effective in producing a $2 / 1$ silicosis than concentrations below that level. ${ }^{9}$ Therefore, short term exposures to high silica concentrations might account for occurrence of silicosis at low cumulative or average exposure levels. If the change in silica concentration in the Scottish colliery were entirely explained by the accidental incursion of the coal getting machinery in a silica richer seam, and no major failure in dust control measures contributed, the observed increase in silica concentration occurred at a presumably constant level of respirable dust-that is, it should have most likely resulted from a greater percentage proportion of silica particles in respirable dust.

A high silica content in respirable dust equates to a larger total physical surface interacting with the biological counterpart in the time unit, at a lesser grade of interference from associated non-silica particles, and for the same deposition pattern associated with an approximately constant average total respirable dust. Under such circumstances, a greater biological effect should be expected.

The importance of the findings of Buchanan et al is threefold. (1) It may be a plausible explanation for intertrade differences in risk of silicosis associated with similar cumulative exposures. (2) It implies the need for tighter schedules of silica monitoring in the workplace, and particularly in quarries and mines, where changes such as as those occurring in the Scottish colliery are to be expected. (3) From a clinical perspective, it poses new questions on whether coal workers' pneumoconiosis (CWP) is truly an individual clinical entity, as it appeared to be from early reports on the British coal mines, or whether it results from undetected silica exposure.

"Fibrogenicity and transforming activity are separate properties of silica"

There is a fourth aspect. This points to a feasible strategy to account for the effect of various exposure circumstances in modifying the association between silica exposure and related health outcomes other than silicosis, particularly lung cancer. The 1997 IARC upgrading of silica to a group 1 human carcinogen did not solve the uncertainty surrounding the circumstances in which silica behaves as a lung carcinogen. ${ }^{10}$ Metaanalysis procedures consider interstudy variability as a random effect. Instead, if such variability results from differences in the biological activity of silica particles inhaled in diverse exposure circumstances, understanding why silica is a lung carcinogen in some workplaces, but not in others (IARC group 3 includes coal dust, which may contain silica at substantial concentrations, as Buchanan et al also report) is crucial to establish safe limits.

Experimental studies have shown fibrogenicity and transforming activity to 
be separate properties of silica. ${ }^{11}$ Mineralogical factors affecting the biological activity of silica particles, discussed by Guthrie, $^{12}$ include type of silica polymorph, enantiomorphic structure of quartz, metal contamination on the quartz surface, and variability in silica surfaces (including size and presence of sorbed cations) affecting the ready availability of ionised silanol groups. Age of silica particles is also relevant, as fresh quartz surfaces generate active oxygen species, due to their abundance in $\mathrm{SIO}^{-}$ radicals. These and other factors, including particle morphology and immune function, modify the biological response to silica at comparable exposure levels. ${ }^{13}$ Moreover, the type of interaction between silica particles and other components of the dust mixing, including other lung carcinogens, might be different from what is expected, as suggested by results from Chinese mines and pottery factories. ${ }^{14}$

To summarise, biological properties of silica are expected to vary: (1) by the mineralogical characteristics of silica itself; (2) by its dilution in total respirable dust; and (3) by the qualitative mineral composition of the dust mix. The history of occupational health has shown that we can reduce uses and intensity of exposure to respirable silica, but we cannot completely eliminate the occupational exposure to a basic component of our physical environment. If silicosis were the risk factor for lung cancer and immune disorders among silica exposed workers, as numerous authors have proposed, enforcing the current limits would protect against lung cancer risk as well. Models such as the one proposed by Buchanan et al, might help in understanding whether this is the case, or alternatively, what else we can do, together with reducing to the lowest achievable limit the environmental concentration of respirable silica, to prevent silica related health effects other than silicosis.

Occup Environ Med 2003;60:157-158

\section{Author's affiliation}

P Cocco, Associate Professor, Department of Public Health, Occupational Health Section, University of Cagliari, Italy

Correspondence to: Prof. P Cocco, Department of Public Health, Occupational Health Section, University of Cagliari, via San Giorgio 12, 09124 Cagliari, Italy; coccop@pacs.unica.it

\section{REFERENCES}

1 NIOSH. Hazard Review: Health effects of occupational exposure to respirable crystalline silica. DHHS-NIOSH publication 2002-129. Cincinnati, $\mathrm{OH}$ : National Institute for Occupational Safety and Health, 2002.

2 Istituto Nazionale per I'Assicurazione contro gli Infortuni sul Lavoro. Rapporto Annuale 2000. Rome: INAIL, 2001.

3 Jeyaratnam J. The transfer of hazardous industries. J Soc Occup Med 1990;40:123-6.

4 Corpuz CL Jr. International Developments and Trends in the Mining Industry. http://www.minesandcommunities.org/
Company/trends.htm. Baguio City

Philippines: Minewatch Asia Pacific, last update October 20, 1999.

5 Steenland K, Brown D. Silicosis among gold miners: exposure-response analyses and risk assessment. Am J Public Health

1995:85:1372-7.

6 Dosemeci M, McLaughlin JK, Chen J-Q, et al. Indirect validation of a retrospective method of exposure assessment used in a nested case-control study of lung cancer and silica exposure. Occup Environ Med 1994:51:136-8.

7 Jin N, Rice C, Dosemeci M, et al. The exposure metric: does a time-weighted calculation of working-lifetime exposure provide a better understanding of disease risk than the cumulative exposure? In: Merlo F, Forastiere F, Goldsmith D, eds. Silica, silicosis, lung cancer and other diseases. Med silicosis, lung cancer and
Lav 2002;93(suppl):S18.

8 Hnizdo E, Sluis-Cremer G. Risk of silicosis in a cohort of White South African gold miners. Am J Ind Med 1993;24:447-57.

9 Buchanan D, Miller BG, Soutar CA. Quantitative relations between exposure to respirable quartz and risk of silicosis. Occup Environ Med 2003;60: 159-64.

10 Cocco P. Multifactorial aetiology of lung cancer among silica-exposed workers. Ann Acad Med Singapore 2001;30:468-74.

11 Mao Y, Daniel LN, Knapton AD, et al. Protective effects of silanol group binding agents on quartz toxicity to rat lung alveolar cells. Appl Occup Environ Hyg 1995:10:1132-7.

12 Guthrie GD Jr. Mineralogical factors affect the biological activity of crystalline silica. Appl Occup Environ Hyg 1995;10:1126-31.

13 Fubini $B$. The chemical basis of the variability of crystalline silica hazard. In: Merlo F, Forastiere F, Goldsmith D, eds. Silica, silicosis, lung cancer and other diseases. Med Lav 2002;93(suppl):S23.

14 Cocco P, Rice CH, Chen J-Q, et al. Lung cancer risk, silica exposure, and silicosis in Chinese mines and pottery factories: the modifying role of other workplace lung carcinogens. Am J Ind Med 2001;40:674-82. 